\title{
Analisis Postur Kerja Pada Karyawan Menggunakan Metode Rula \\ (Studi kasus Area Control Room, Joint Operating Body Pertamina-Medco E\&P Tomori Sulawesi)
}

\author{
Muh. Ridwan Malik*‡, Moh Alwi**, Eduart Wolok***, Abdul Rasyid****
}

*,**, ${ }^{* *},{ }^{* * * *}$ Jurusan Teknik Industri Fakultas Teknik, Universitas Negeri Gorontalo, Jl. Jenderal Sudirman No.6 Kota Gorontalo, Indonesia 96128

(muh.ridwanmalik2016@gmail.com,moh.alwi16@gmail.com, eduart@ung.ac.id, abdul.rasyid@ung.ac.id)

¥Penulis Koresponden; Muh. Ridwan Malik, Tel: +62 8152465 1733, muh.ridwanmalik2016@gmail.com

Dikirim: 16.03.2021 Disetujui: 19.04.2021 Diterbitkan: 01.05.2021

\begin{abstract}
Abstrak- Joint Operating Body (JOB) merupakan kegiatan operasional yang dilakukan oleh badan operasi bersama JOB Pertamina - Medco E\&P Tomori Sulawesi adalah badan kerjasama operasi yang dibentuk berdasarkan Production Sharing Contract antara perusahaan PT. Pertamina Hulu Energi dengan PT. Medco E\&P Tomori Sulawesi. Salah satu indikasi adanya gangguan keselamatan dan kesehatan pada pekerja adalah adanya kelelahan atau keluhan musculoskeletal atau sistem otot rangka seperti adanya rasa nyeri pada tubuh baik saat bekerja maupun setelah bekerja dan rasa tidak nyaman pada otot. Salah satu penyebab adanya gangguan pada otot rangka yang ditimbulkan dari pekerjaan yang dilakukan secara statis yaitu posisi dan postur tubuh kerja yang tidak sesuai, seperti yang dialami staff atau karyawan bagian Production di JOB Pertamina-Medco E\&P Tomori Sulawesi, yang melakukan pekerjaan dengan posisi yang dilakukan secara statis dalam kurun waktu yang cukup lama yakni \pm 12 jam sehari. Tujuannya yaitu untuk mengetahui level resiko pada posisi dan postur kerja karyawan Area Control Room di JOB Pertamina-Medco E\&P Tomori Sulawesi. Hasil perhitungan dengan metode RULA didapatkan 6 operator berada pada level action 3 dan 3 operator berada pada level action 2. Analisis postur kerja Operator JOB Pertamina-Medco E\&P Tomori Sulawesi dapat disimpulkan bahwa hasil analisis Rula 9 Operator yang merupakan karyawan JOB Pertamina-Medco E\&P Tomori Sulawesi, 6 dari 9 Operator berapa pada level resiko "Sedang" dengan nilai skor akhir diperolah 5-6 artinya yang menunjukan pemeriksaan dan perubahan posisi duduk perlu segera dilakukan. dan 3 dari 9 Operator berada pada level resiko "Kecil/Rendah" dengan Nilai sekor akhir diperoleh 3-4 artinya menunjukan bahwa resiko rendah dan perubahan diperlukan.
\end{abstract}

Kata Kunci : RULA, Postur kerja, Pekerja ruang kontrol

\author{
Posture Analysis On Employees Using The Rula Method \\ (Case study Area Control Room, Joint Operating Body Pertamina-Medco E\&P Tomori Sulawesi)
}

\begin{abstract}
Joint Operating Body (JOB) is an operational activity carried out by the joint operating agency JOB Pertamina - Medco E\&P Tomori Sulawesi is a joint operation body formed based on the Production Sharing Contract between PT. Pertamina Hulu Energi and PT. Medco E\&P Tomori Sulawesi. One indication of safety and health problems in workers is fatigue or complaints of the musculoskeletal or skeletal muscle system, such as pain in the body both during work and after work and discomfort in the muscles. One of the causes of disturbance in the skeletal muscles caused by work that is done statically is the position and posture of the work body that is not appropriate, as experienced by staff or employees of the Production section at JOB Pertamina-Medco E\&P Tomori Sulawesi, who do
\end{abstract}


work in the position they are doing statically over a long period of time, namely \pm 12 hours a day. The goal is to determine the level of risk in the position and work posture of the Area Control Room employees at JOB PertaminaMedco E\&P Tomori Sulawesi. The results of calculations using the RULA method show that 6 operators are at action level 3 and 3 operators are at action level 2. Analysis of the work posture of JOB Pertamina-Medco E\&P Tomori Sulawesi Operators, it can be concluded that the results of the analysis of Rula 9 Operators who are JOB PertaminaMedco E\&P Tomori Sulawesi employees, 6 out of 9 Operators at the risk level "Medium" with the final score obtained 5-6 means which indicates that an examination and a change in sitting position need to be done immediately. and 3 out of 9 Operators are at a "Low" risk level with a final score of 3-4 meaning that the risk is low and change is required.

Key words : RULA, work posture, Control room workers

\section{Pendahuluan}

Kondisi pekerja dikatakan tidak aman apabila keselamatan dan kesehatan pekerja mulai terganggu (Aghnia, 2017). Salah satu indikasi adanya gangguan keselamatan dan kesehatan pada pekerja adalah adanya kelelahan atau keluhan musculoskeletal atau sistem otot rangka seperti adanya rasa nyeri pada tubuh baik saat bekerja maupun setelah bekerja dan rasa tidak nyaman pada otot.

Salah satu penyebab adanya gangguan pada otot rangka yang ditimbulkan dari pekerjaan yang dilakukan secara statis yaitu posisi dan postur tubuh kerja yang tidak sesuai, seperti yang dialami staff atau karyawan bagian Production di JOB Pertamina-Medco E\&P Tomori Sulawesi, yang melakukan pekerjaan dengan posisi yang dilakukan secara statis dalam kurun waktu yang cukup lama yakni \pm 12 jam sehari. Hal ini tidak menutup kemungkinan akan terjadi keluhan sakit pada bagian tubuh pekerja. Sehingga, pada studi kasus ini perlu diadakannya penelitian untuk mengantisipasi adanya resiko keluhan pada bagian otot yang disebabkan oleh postur kerja yang tidak baik. Sehingga, pada studi kasus ini perlu diadakannya penelitian untuk mengetahui level resiko postur dan posisi tubuh kerja pada karyawan JOB Pertamina-Medco E\&P Tomori Sulawesi.

Menurut Briansah (2018), Rapid Upper Limb Assessment (RULA) adalah sebuah metode untuk menilai postur, gaya, dan gerakan suatu aktivitas kerja yang berkaitan dengan penggunaan anggota tubuh bagian atas (upper limb). Metode ini dikembangkan untuk menyelidiki resiko kelainan yang akan dialami oleh seorang pekerja dalam melakukan aktivitas kerja yang memanfaatkan anggota tubuh bagian atas (upper limb). Dari hasil wawancara 9 responden karyawan pada bagian control room 2 diantaranya mengalami keluhan dibagian leher dan punggung. Sheingga Tujuan dari Penelitian ini yaitu untuk dapat mengetahui level resiko pada posisi dan posture kerja karyawan di Area Control Room Joint Operating Body Pertamina-Medco E\&P Tomori Sulawesi.

\section{Landasan Teori}

Pada bab ini penulis dapat membagi 2 atau 3 subbab. Penulis menyampaikan metode penelitian/ kajian yang digunakan mencakup alat, bahan dan hal yang menyangkut teknis penelitian. Menjelaskan dimana dan kapan penelitian dilakukan. Menjelaskan bagaimana mengambil sample dan dianalisis dengan metode apa.

Cara terbaik untuk menggunakan templet ini adalah menyiapkan terlebih dahulu isi naskah Anda pada sebuah file terpisah. Kemudian salin dan tempel bagian per bagian dari isi naskah ke dalam templet ini tanpa menyertakan bagian gambar dan tabel terlebih dahulu. Jika telah menyalin semua isi naskah akhiri dengan meletakkan gambar dan tabel di posisi yang sesuai.

\subsection{Kelelahan Kerja}

\section{a. Definisi Kelelahan Kerja}

Ada beberapa teori tentang kelelahan yakni :

1. Kelelahan kerja merupakan menurunnya proses efisiensi, performa kerja,dan berkurangnya kekuatan/ketahanan fisik tubuh untuk terus melanjutkan kegiatan yang harus dilakukan (Wignjosobroto, 2000) dalam Briansah (2018).

2. Kelelahan kerja adalah suatu fenomena yang kompleks yang disebabkan oleh faktor biologis pada proses kerja serta dipengaruhi oleh faktor internal maupun eksternal oleh Setyawati (2010) dalam Briansah (2018).

\section{b. Jenis Kelelahan Kerja}

Menurut Depkes (2007) kelelahan ada tiga jenis yaitu antara lain :

a) Kelelahan Fisik

Kelelahan fisik akibat kerja yang berlebihan, dimana masih dapat dikompensasi dan diperbaiki performansnya seperti semula. Kalau tidak terlalu berat kelelahan ini bisa hilang setelah istirahat dan tidur yang cukup.

b) Kelelahan yang Patologis 
Kelelahan ini tergabung dengan penyakit yang diderita, biasanya muncul tiba-tiba dan berat gejalanya.

c) Psikologis dan Emotional Fatique

Kelelahan ini adalah bentuk yang umum. Kemungkinan merupakan jenis mekanisme melarikan diri dari kenyataan pada penderita psikosomatik. Semangat yang baik dan motivasi kerja akan mengurangi angka kejadiannya di tempat kerja.

c. Gejala kelelahan

Kelelahan kerja pada umumnya dikeluhkan sebagai kelelahan dalam sikap, orientasi, dan penyesuaian di tempat kerja yang dialami pekerja yang mengalami kelelahan kerja oleh Setyawati (2010) dalam Hariyati (2011).

\subsection{Postur Kerja}

Postur kerja adalah sikap tubuh saat bekerja. Sikap kerja yang berlainan akan menghasilkan kekuatan yang berbeda. Pada saat bekerja postur dilakukan dirancang agar terjadi alamiyah sehingga dapat mengurangi timbulnya cedera muscoluskeletal (Masitoh, 2016). Kenyamanan terwujud apabila pekerja melakukan postur kerja yang sesuai dan nyaman. Dalam tubuh manusia terdapat jenis gaya, yaitu (Masitoh, 2016) :

1. Gaya gravitasi, yaitu gaya yang melalui pusat massa dari tiap segmen tubuh manusia dengan arah kebawah $(\mathrm{F}=\mathrm{m} \cdot \mathrm{g})$.

2. Gaya Reaksi, yaitu gaya yang terjadi akibat beban pada segmen tubuh atau berat segmen tubuh itu sendiri.

3. Gaya otot, yaitu gaya yang terjadi pada bagian sendi, baik akibat gesekan sendi atau akibat gaya pada otot yang melekat pada sendi. Gaya ini menggambarkan besarnya gaya momen otot. 2016):

Tubuh manusia terdiri dari 6 link yaitu (Masitoh,

1. Link lengan bawah, dibatasi joint telapak tangan dan siku.

2. Link lengan atas, dibatasi joint siku dan bahu.

3. Link punggung, dibatasi joint bahu dan pinggul.

4. Link paha, dibatasi joint pinggul dan lutut.

5. Link betis, dibatasi joint lutut dan mata kaki.

6. Link kaki, dibatasi joint mata kaki dan telapak kaki.

Pengukuran waktu adalah pekerjaan mengamati dan mencatat waktu-waktu kerjanya baik setiap elemen ataupun siklus dengan menggunakan alat-alat yang telah disiapkan (M. Ade Rafian dan Ahmad Muhsin, 2017). Postur kerja yang baik sangat ditentukan oleh pergerakan organ tubuh saat bekerja. Pergerakan yang dilakukan saat bekerja meliputi: flexion, extension, abduction, adduction, rotation, pronation dan supination. Flexion adalah gerakan dimana sudut antara dua tulang terjadi pengurangan., extension adalah gerakan merentangkan dimana terjadi peningkatan sudut antar dua tulang. Abduction adalah gerakan menyamping menjauhi dari sumbu tengah tubuh. Adduction adalah pergerakan kearah sumbu tengah tubuh. Rotation adalah perputaran bagian atas lengan atau kaki depan. Pronation adalah perputaran bagian tengah (menuju kedalam) dari anggota tubuh. Supination adalah perputaran kea rah samping (menuju luar) dari anggota tubuh (Rinawati dan Romadona, 2016).

Suatu tindakan yang diambil pekerja dalam melakukan pekerjaan disebut dengan postur atau sikap kerja (wati, 2016). Terdapat 3 klasifikasi sikap dalam bekerja :

\section{1) Sikap kerja duduk}

Sikap kerja duduk dalam melakukan suatu pekerjaan dapat menimbulkan masalah muskuloskele tal, terutama masalah pada bagian punggung karena terdapat tekanan pada tulang bagian belakang, keuntungan bekerja dengan sikap kerja duduk adalah dapat mengurangi pemakaian energi dan beban statis pada kaki.

\section{2) Sikap Kerja Berdiri}

Sikap kerja berdiri adalah sikap siaga, baik secara fisik maupun mental, sehingga aktivitas kerja dapat dilakukan lebih cepat, kuat dan teliti namun sikap kerja berdiri dapat menimbulkan berbagai masalah seperti menyebabkan kelelahan, nyeri dan terjadi fraktur pada otot tulang belakang.

\section{3) Sikap kerja duduk berdiri}

Sikap kerja duduk berdiri merupakan kombinasi kedua sikap kerja untuk mengurangi kelelahan otot karena sikap paksa dalam satu posisi kerja. posisi duduk berdiri merupakan posisi yang lebih baik dibandingkan posisi duduk atau posisi berdiri saja. Penerapan sikap kerja duduk-berdiri memberikan keuntungan di sektor industri dimana tekanan pada tulang belakang dan pinggan $30 \%$ lebih rendah dibandingkan dengan posisi duduk maupun berdiri saja terus-menerus (Tarwaka, 2010).

\subsubsection{Sikap Kerja Duduk}

\section{a. Definisi Sikap Kerja Duduk}

Duduk memerlukan lebih sedikit energi daripada berdiri, karena hal itu dapat mengurangi banyaknya beban otot statis pada kaki. Tekanan pada tulang belakang akan meningkat pada saat duduk, dibandingkan dengan saat berdiri ataupun berbaring. 
Jika diasumsikan, tekanan tersebut sebesar $100 \%$, cara duduk yang tegang atau kaku (erect posture) dapat menyebabkan tekanan mencapai $140 \%$ dan cara duduk yang dilakukan secara membungkuk ke depan menyebabkan tekanan tersebut sampai 190\%. Sikap duduk yang tegang lebih banyak memerlukan aktivitas otot atau saraf belakang daripada sikap duduk yang condong kedepan. Posisi duduk pada otot rangka (muskuloskeletal) dan tulang belakang yang tidak ergonomis dapat menimbulkan keluhan terutama pada nyeri pinggang, dalam hal ini sandaran kursi yang digunakan harus dapat menahan, agar terhindar dari rasa nyeri dan cepat lelah.

Sikap kerja duduk merupakan pekerjaan ringan, namun jika pekerjaan dengan duduk dilakukan dalam waktu yang lama bahkan setiap hari, maka otot dapat mengalami ketegangan pembebanan otot statis. Beban otot statis terjadi ketika otot dalam keadaan tegang tanpa menghasilkan gerakan tangan atau kaki sekalipun.

Beberapa keuntungan bekerja yang dilakukan sambil duduk adalah sebagai berikut :

1) Berkurangnya kelelahan pada kaki

2) Terhindarnya sikap-sikap tidak alamiah

3) Berkurangnya pemakaian energi

4) Berkurangnya tingkat keperluan sirkulasi darah

Adapun kerugian yang dilakukan akibat bekerja sambil duduk yaitu:

1)Melembeknya otot-otot perut

2)Melengkungnya punggung

3) Tidak baik bagi alat-alat dalam, khususnya peralatan pencernaan, jika posisi dilakukan membungkuk.

Beberapa pertimbangan ergonomis pada sikap kerja duduk adalah sebagai berikut :

1) Mengurangi keharusan tenaga kerja bekerja dengan sikap dan posisi membungkuk dalam jangka waktu yang lama atau dengan frekuensi kegiatan yang berulang-ulang.

2) Tenaga kerja tidak seharusnya menggunakan jarak jangkauan maksimum yang dilakukan. Posisi kerja diatur dalam jarak jangkauan normal. Hal ini membuat tenaga kerja cukup leluasa mengatur tubuhnya agar memperoleh sikap dan posisi kerja yang nyaman.

3) Tenaga kerja tidak seharusnya duduk saat bekerja untuk waktu yang lama dengan kepala, leher, dada atau kaki berada dalam sikap atau posisi miring.

4) Tenaga kerja tidak seharusnya dipaksa bekerja dalam frekuensi atau periode waktu yang lama dengan tangan atau lengan berada dalam posisi diatas level siku yang normal.

b. Pengukuran Sikap Kerja Duduk
Ada beberapa cara yang telah diperkenalkan dalam melakukan evaluasi ergonomi untuk mengetahui sikap kerja yang berhubungan antara tekanan fisik dengan risiko keluhan otot rangka skeletal .Alat ukur ergonomi yang digunakan cukup banyak dan bervariasi.

Salah satu metode yang dapat digunakan dalam observasi postur tubuh yang berkaitan dengan risiko gangguan sistem muskuloskeletal adalah metode RULA (Rapid Upper Analysis System). Rapid Upper Analysis System (RULA) adalah metoda yang dirancang oleh Lynn McAtamney dan Nigel Corlett (Lahay, 2017). Metode RULA merupakan suatu metode dengan menggunakan target postur tubuh untuk mengestimasi risiko terjadinya gangguan otot skeletal, khususnya pada anggota tubuh bagian atas (upper limb disorders), seperti adanya gerakan repetitif, pekerjaan diperlukan pengerahan kekuatan, aktivitas otot statis pada otot skeletal.

Adapun tujuan dari metode RULA adalah sebagai berikut :

a. Menyediakan perlindungan yang cepat dalam pekerjaan

b. Mengidentifikasi usaha yang dibutuhkan otot yang berhubungan dengan postur tubuh saat kerja.

c. Memberikan hasil yang dapat dimasukkan dalam penilaian ergonomi yang luas.

d. Mendokumentasikan postur tubuh saat kerja, dengan ketentuan:

e. Tubuh dibagi menjadi dua grup yaitu A (lengan atas dan bawah dan pergelangan tangan) dan B (leher, tulang belakang, dan kaki).

f. Jarak pergerakan dari setiap bagian tubuh diberi nomor.

g. Scoring dilakukan terhadap kedua sisi tubuh, kanan dan kiri.

\section{Metodelogi}

Pelaksanaan kerja praktek dilaksanakan di Departemen Health Safety and Environment (HSE) JOB Pertamina-Medco E\&P Tomori Sulawesi. Analisa yang dilakukan pada kerja praktek yaitu untuk mengetahui mengetahui level resiko pada posisi dan postur kerja karyawan di Area Control Room dengan menggunakan metode Rapid Upper Analysis System (RULA).

\section{Hasil dan Pembahasan}


a) Data Kondisi Postur Kerja

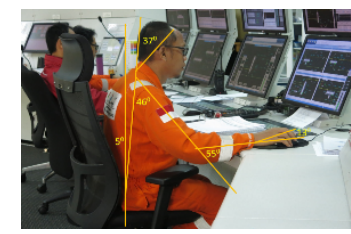

Gambar 1. Operator 1

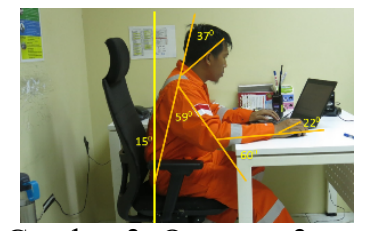

Gambar 3. Operator 3

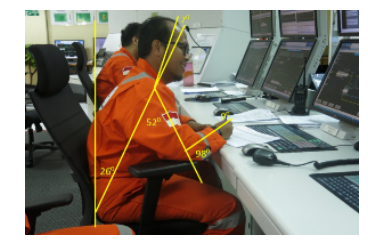

Gambar 5. Operator 5

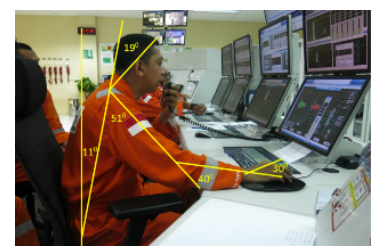

Gambar 7. Operator 7

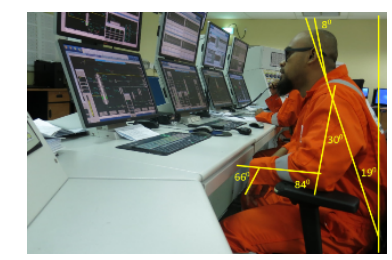

Gambar 9. Operator 9

\section{b) Penilaian Postur Tubuh}

Berikut adalah hasil penilaian postur kerja pada 9 Operator JOB Pertamina-Medco E\&P Tomori Sulawesi :

Pengolahan Data Perhitungan Skor Postur Kerja pada Operator 1:

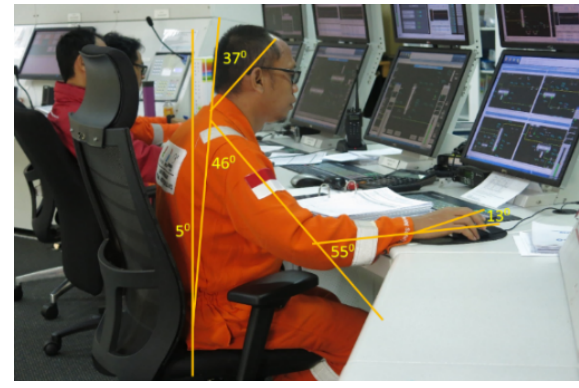

Gambar 7. Operator 1

\section{$>$ Postur tubuh grup A}

Tabel 1. Nilai grup A Operator 1

\begin{tabular}{|c|c|}
\hline Postur Kerja & Nilai \\
\hline Lengan atas & 3 \\
\hline Lengan bawah & 2 \\
\hline $\begin{array}{c}\text { Pergelangan } \\
\text { Tangan }\end{array}$ & 2 \\
\hline $\begin{array}{c}\text { Putaran Pergelangan } \\
\text { Tang }\end{array}$ & 1 \\
\hline
\end{tabular}

Tabel 2. RULA Skor Grup A Operator 1

\begin{tabular}{|c|c|c|c|c|c|c|c|c|c|}
\hline \multirow{4}{*}{$\begin{array}{c}\text { Lengan } \\
\text { atas }\end{array}$} & \multirow{4}{*}{$\begin{array}{c}\text { Lengan } \\
\text { bawah }\end{array}$} & \multicolumn{8}{|c|}{ Pergelangan tangan } \\
\hline & & \multicolumn{2}{|c|}{1} & \multicolumn{2}{|c|}{$\overline{2}$} & \multicolumn{2}{|c|}{3} & \multicolumn{2}{|c|}{4} \\
\hline & & \multicolumn{8}{|c|}{$\begin{array}{c}\text { Putaran Pergelangan } \\
\text { Tangan }\end{array}$} \\
\hline & & 1 & 2 & 1 & 2 & 1 & 2 & 1 & 2 \\
\hline \multirow{3}{*}{1} & 1 & 1 & 2 & 2 & 2 & 2 & 3 & 3 & 3 \\
\hline & 2 & 2 & 2 & 2 & 2 & 3 & 3 & 3 & 3 \\
\hline & 3 & 2 & 3 & 3 & 3 & 3 & 3 & 4 & 4 \\
\hline \multirow{3}{*}{2} & 1 & 2 & 3 & 3 & 3 & 3 & 4 & 4 & 4 \\
\hline & 2 & 3 & 3 & 3 & 3 & 3 & 4 & 4 & 4 \\
\hline & 3 & 3 & 4 & 4 & 4 & 4 & 4 & 5 & 5 \\
\hline \multirow{3}{*}{3} & 1 & 3 & 3 & 4 & 4 & 4 & 4 & 5 & 5 \\
\hline & 2 & 3 & 4 & 4 & 4 & 4 & 4 & 5 & 5 \\
\hline & 3 & 4 & 4 & 4 & \begin{tabular}{|l|}
4 \\
\end{tabular} & 4 & 5 & 5 & 5 \\
\hline \multirow{3}{*}{4} & 1 & 4 & 4 & 4 & 4 & 4 & 5 & 5 & 5 \\
\hline & 2 & 4 & 4 & 4 & 4 & 4 & 5 & 5 & 5 \\
\hline & 3 & 4 & 4 & 4 & 5 & 5 & 5 & 6 & 6 \\
\hline \multirow{3}{*}{5} & 1 & 5 & 5 & 5 & 5 & 5 & 6 & 6 & 7 \\
\hline & 2 & 5 & 6 & 6 & 6 & 6 & 7 & 7 & 7 \\
\hline & 3 & 6 & 6 & 6 & 7 & 7 & 7 & 7 & 8 \\
\hline \multirow{3}{*}{6} & 1 & 7 & 7 & 7 & 7 & 7 & 8 & 8 & 9 \\
\hline & 2 & 8 & 8 & 8 & 8 & 8 & 9 & 9 & 9 \\
\hline & 3 & 9 & 9 & 9 & 9 & 9 & 9 & 9 & 9 \\
\hline
\end{tabular}



a. Skor aktivitas
: Postur statik, satu atau lebih bagian tubuh statis/diam diberi
b. Skor beban Skor 1 berselang, diberi nilai 0
c. Total Skor A: = Skor A + Skor Aktivitas + Skor
: Pembebanan statis $<2 \mathrm{~kg}$ atau Beban

$$
\begin{aligned}
& =4+1+0 \\
& =5
\end{aligned}
$$

\section{$>$ Postur Tubuh Grup B}

Tabel 3. Nilai Grup A Operator 1

\begin{tabular}{|c|c|}
\hline Postur Tubuh & Nilai \\
\hline Leher & 3 \\
\hline Punggung & 4 \\
\hline kaki & 1 \\
\hline
\end{tabular}

\begin{tabular}{|c|c|c|c|c|c|c|c|c|c|c|c|c|}
\hline \multirow{4}{*}{ Leher } & \multicolumn{12}{|c|}{ Punggung } \\
\hline & \multicolumn{3}{|c|}{1} & \multicolumn{2}{|c|}{2} & \multicolumn{2}{|c|}{3} & \multicolumn{2}{|l|}{4} & \multicolumn{2}{|c|}{5} & \multirow[t]{2}{*}{6} \\
\hline & \multicolumn{11}{|c|}{ Kaki } & \\
\hline & 1 & 2 & 1 & 2 & 1 & 2 & 1 & 2 & 1 & 2 & 1 & 2 \\
\hline 1 & 1 & 3 & 2 & 3 & 3 & 4 & 5 & 5 & 6 & 6 & 7 & 7 \\
\hline 2 & 2 & 3 & 2 & 3 & 4 & 5 & 5 & 5 & 6 & 7 & 7 & 7 \\
\hline 3 & 3 & 3 & 3 & 4 & 4 & 5 & 5 & 6 & 6 & 7 & 7 & 7 \\
\hline 4 & 5 & 5 & 5 & 6 & 6 & 7 & 7 & 7 & 7 & 7 & 8 & 8 \\
\hline 5 & 7 & 7 & 7 & 7 & 7 & 8 & 8 & 8 & 8 & 8 & 8 & 8 \\
\hline 6 & 8 & 8 & 8 & 8 & 8 & 8 & 8 & 9 & 9 & 9 & 9 & 9 \\
\hline
\end{tabular}

Tabel 4. RULA Skor Grup B Operator 1

\section{a. Skor aktivitas}

b. Skor beban/ Tenaga

c. Total Skor B

\begin{abstract}
: Postur statik, satu atau lebih bagian tubuh statis/diam diberi skor 1
\end{abstract}

: Pembebanan statis $<2 \mathrm{~kg}$ atau berselang, maka diberi nilai 0

$:=$ Skor B + Skor Aktivitas +

Skor Beban

$=5+1+0$

$=6$

\section{Final score}

\begin{tabular}{|c|c|c|c|c|c|c|c|c|}
\hline & \multicolumn{8}{|c|}{ Nilai A } \\
\hline \multirow{9}{*}{$\frac{\infty}{\pi}$} & & 1 & 2 & 3 & 4 & 5 & 6 & $7+$ \\
\hline & 1 & 1 & 2 & 3 & 3 & 4 & 5 & 5 \\
\hline & 2 & 2 & 2 & 3 & 4 & 4 & 5 & 5 \\
\hline & 3 & 3 & 3 & 3 & 4 & 4 & 5 & 6 \\
\hline & 4 & 3 & 3 & 3 & 4 & 5 & 6 & 6 \\
\hline & 5 & 4 & 4 & 4 & 5 & 6 & 7 & 7 \\
\hline & 6 & 4 & 4 & 5 & 6 & 6 & 7 & 7 \\
\hline & 7 & 5 & 5 & 6 & 6 & 7 & 7 & 7 \\
\hline & $8+$ & 5 & 5 & 6 & 7 & 7 & 7 & 7 \\
\hline
\end{tabular}

Tabel 5. RULA Final Score Operator 1

Hasil final skor untuk Operator 1 adalah 6, dapat dilihat pada table 3.5

\begin{tabular}{|l|l|l|}
\hline FINAL & SCORE & \multicolumn{1}{|c|}{ TINGKAT RESIKO } \\
\hline 1 & $1-2$ & $\begin{array}{l}\text { Resiko diabaikan, tidak perlu } \\
\text { penanganan }\end{array}$ \\
\hline 2 & $3-4$ & $\begin{array}{l}\text { Resiko rendah, perubahan } \\
\text { dibutuhkan }\end{array}$ \\
\hline 3 & $5-6$ & $\begin{array}{l}\text { Resiko sedang, pananganan } \\
\text { lebih lanjut, butuh Perubahan }\end{array}$ \\
\hline 4 & $6+$ & $\begin{array}{l}\text { Sangat beresiko, lakukan } \\
\text { perubahan sekarang }\end{array}$ \\
\hline
\end{tabular}

Berdasarkan hasil final skor untuk Operator 1 didapatkan bahwa nilai skor 6 berada pada level tindakan 3, yang menunjukan pemeriksaan dan perubahan perlu segera dilakukan. Untuk penilaian responden 2 dan selanjutnya dapat dilihat pada table rekapitulasi dibawah ini.

Tabel 7. Rekapitulasi hasil penilaian RULA

\begin{tabular}{|c|c|c|l|l|}
\hline No & Responden & $\begin{array}{l}\text { Skor } \\
\text { Akhir }\end{array}$ & $\begin{array}{l}\text { Level } \\
\text { Resiko }\end{array}$ & Tindakan Perbaikan \\
\hline 1. & $\begin{array}{c}\text { Responden } \\
1\end{array}$ & 6 & 3/Sedang & $\begin{array}{l}\text { Dilakukan perubahan } \\
\text { posisi duduk dalam } \\
\text { waktu dekat }\end{array}$ \\
\hline 2. & $\begin{array}{c}\text { Responden } \\
2\end{array}$ & 6 & $3 /$ Sedang & $\begin{array}{l}\text { Dilakukan perubahan } \\
\text { posisi duduk dalam } \\
\text { waktu dekat }\end{array}$ \\
\hline 3. & Responden & 5 & $3 /$ Sedang & Dilakukan perubahan \\
\hline
\end{tabular}




\begin{tabular}{|c|c|c|l|l|}
\hline & 3 & & & $\begin{array}{l}\text { posisi duduk dalam } \\
\text { waktu dekat }\end{array}$ \\
\hline 4. & $\begin{array}{c}\text { Responden } \\
4\end{array}$ & 6 & $3 /$ Sedang & $\begin{array}{l}\text { Dilakukan perubahan } \\
\text { posisi duduk dalam } \\
\text { waktu dekat }\end{array}$ \\
\hline 5. & $\begin{array}{c}\text { Responden } \\
5\end{array}$ & 5 & $3 /$ Sedang & $\begin{array}{l}\text { Dilakukan perubahan } \\
\text { posisi duduk dalam } \\
\text { waktu dekat }\end{array}$ \\
\hline 6. & $\begin{array}{c}\text { Responden } \\
6\end{array}$ & 5 & $3 /$ Sedang & $\begin{array}{l}\text { Dilakukan perubahan } \\
\text { posisi duduk dalam } \\
\text { waktu dekat }\end{array}$ \\
\hline 7. & $\begin{array}{c}\text { Responden } \\
7\end{array}$ & 4 & 2/Rendah & $\begin{array}{l}\text { Dilakukan Perubahan } \\
\text { Posisi duduk beberap } \\
\text { a waktu kedepan }\end{array}$ \\
\hline 8. & $\begin{array}{c}\text { Responden } \\
8\end{array}$ & 4 & 2/Rendah & $\begin{array}{l}\text { Dilakukan Perubahan } \\
\text { Posisi duduk beberapa } \\
\text { waktu kedepan }\end{array}$ \\
\hline 9. & $\begin{array}{c}\text { Responden } \\
9\end{array}$ & 4 & 2/Rendah & $\begin{array}{l}\text { Dilakukan Perubahan } \\
\text { Posisi duduk beberapa } \\
\text { waktu kedepan }\end{array}$ \\
\hline
\end{tabular}

\section{c) Pembahasan}

Berdasarkan tabel rekapitulasi hasil Rula dari Responden yang merupakan Operator JOB PertaminaMedco E\&P Tomori Sulawesi 6 dari 9 Operator berada pada level resiko "Sedang" dengan nilai skor akhir diperolah 5-6 dan, dan 3 dari 9 Operator berada pada level resiko "Kesil/Rendah" dengan Nilai skor akhir diperoleh adalah 3 dan 4 .

Dilihat dari hasil pengamatan dilapangan dan penilaian RULA peneliti memberikan rekomendasi posisi duduk yang baik berdasarkan analisis RULA menggunakan Sofrware Catia V5R21 seperti pada gambar 3.19 berikut:

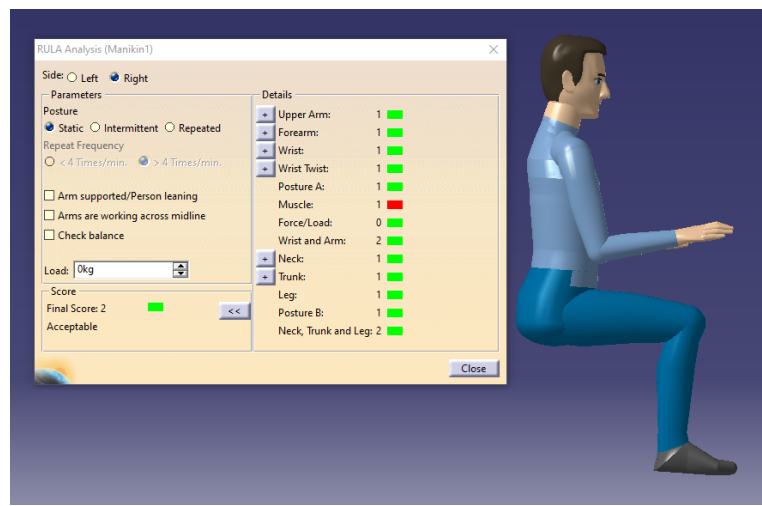

Gambar 7. Output Software CATIA

(Sumber: Hasil pengolahan data dengan software CATIA V5R21)

Tabel 8. Rekapitulasi hasil penilaian RULA

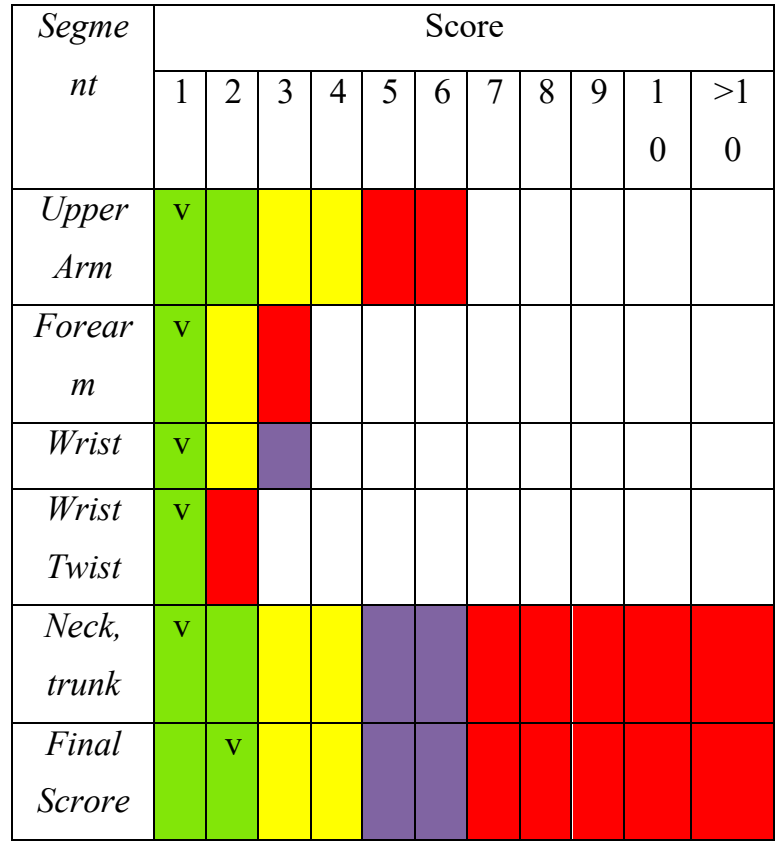

Berdasarkan Hasil CATIA diatas dapat diketahui bahwa posisi duduk yang baik (rekomendasi peneliti), tingkat kelelahan dari pekerja selama bekerja dapat direduksi. Hal ini dapat dilihat dari hasil akhir pada posisi sebelumnya yang terjadi pada 9 responden pekerja yang semula 4, 5 bahkan 6 dapat berkurang, dengan nilai yang dihasilkan 2 (postur yang direkomendasikan) serta didukung oleh kursi yang adjustable.

\section{Kesimpulan dan Saran}

\section{Kesimpulan}

Berdasarkan hasil dan pembahasan terkait analisis postur kerja Operator JOB Pertamina-Medco E\&P Tomori Sulawesi dapat disimpulkan bahwa hasil analisis Rula 9 Operator yang merupakan karyawan JOB Pertamina-Medco E\&P Tomori Sulawesi, 6 dari 9 Operator berapa pada level resiko "Sedang" dengan nilai skor akhir diperolah 5-6 artinya yang menunjukan pemeriksaan dan perubahan posisi duduk perlu segera dilakukan. dan 3 dari 9 responden berada pada level resiko "Kecil/Rendah" dengan Nilai sekor akhir diperoleh adalah 3 dan 4 artinya menunjukan bahwa resiko rendah dan perubahan diperlukan.

\section{Saran}

Berdasarkan kesimpulan terkait analisis postur kerja karyawan JOB Pertamina-Medco E\&P Tomori Sulawesi dengan metode Rula maka peneliti menyarankan agar:

1. Pekerja yang bekerja di Control Room agar bisa menerapkan postur tubuh yang baik

2. Pekerja diharapkan sering melakukan peregangan otot-otot. 


\section{Ucapan Terima Kasih}

Ucapan terima kasih wajib diberikan kepada para pihak atau reviewer atau yang membantu/mendukung /terlibat dalam proses penyusunan naskah.

\section{Daftar Pustaka}

[1] Aghnia, Agin Darojatul. 2017. "Pemetaan Keluhan Musculoskeletal Disorders Berdasarkan Faktor Risiko Pekerjaan Pekerja Produksi Bakso CV Unique Mandiri Perkasa Bekasi". Universitas Islam Negeri Syarif Hidayatullah. Jakarta.

[2] Briansah, Alen Okvan. 2018. "Analisa Postur Kerja Yang Terjadi Untuk Aktivitas Dalam Proyek Konstruksi Bangunan Dengan Metode RULA Di CV Basani". Universitas Islam Indonesia. Yogyakarta.

[3] Departemen Kesehatan RI. 2007. Pedoman Manajemen Kesehatan dan Keselamatan Kerja (K3) Di Rumah Sakit. Keputusan Menteri Kesehatan RI No.432/MENKES/SK/IV/2007.

[4] Hariyati Maulina. 2011. Pengaruh Beban Kerja Terhadap Kelelahan Kerja Pada Pekerja Linting Manual Di PT Djitoe Indonesia Tobacco Surakarta. Universitas Sebelas Maret. Surakarta.

[5] JOB Pertamina - Mdco E\&P Tomori Sulawesi. 2013.
Pedoman Operasi

[6] Lahay, Idham Halid, Hasanuudin, dan Hendra Uloli. 2017. "Penilaian Postur Kerja Pada Pekerja Pembuat Batako Di Gorontalo". Gorontalo.

[7] Masitoh, D. (2016). Analisis Postur Tubuh dengan Metode Rula Pada Pekerja Welding di Area Sub Assy PT. Fuji Technica Indonesia Karawang. Tugas Akhir Universitas Sebelas Maret.

[8] Pangaribuan, Dina Meliana. 2009. “Analisa Postur Kerja dengan Metode RULA Pada Pegawai Bagian Pelayanan Perpustakaan USU Medan". Medan.

[9] Taofiq, Iqbal Muharram dan Mauluddin, Yusuf (2015) "Evaluasi ergonomi menggunakan metode rula (rapid upper limb assessment) untuk mengidentifikasi Alat bantu pada mesin roasting kopi” Jurnal Kalibrasi Sekolah Tinggi Teknologi Garut.

[10] Wati, Destiana Herdi. 2016. "Hubungan Postur Kerja Duduk Dengan Kelelahan Kerja Tenaga Kerja Batik Tulis Di Masaran Sragen". Skripsi. Universitas Sebelas Maret. Surakarta.

[11] Wijaya, Irfan Syah Aji dan Ahmad Muhsin. 2018. “Analisa Postur Kerja Dengan Metode Rapid Upper Limb Assessment (Rula) Pada Oparator Mesin Extruder Di Stasiun Kerja Extruding Pada Pt Xyz". Universitas Pembangunan Nasional "Veteran". Yogyakarta. 